\title{
Correction to: DR15-DQ6 remains dominantly protective against type 1 diabetes throughout the first five decades of life
}

\author{
Nicholas J. Thomas ${ }^{1,2}$ (D) J John M. Dennis ${ }^{1}$ (D) $\cdot$ Seth A. Sharp ${ }^{1}$ (D) $\cdot$ Akaal Kaur $^{3} \cdot$ Shivani Misra $^{3}$ (D) $\cdot$ Helen C. Walkey $^{3}$ (D) \\ Desmond G. Johnston ${ }^{3}$ (D) - Nick S. Oliver ${ }^{3}$ (D) - William A. Hagopian ${ }^{4}$ (D) - Michael N. Weedon ${ }^{1}$ (D) \\ Kashyap A. Patel ${ }^{1,2}$ (1D) Richard A. Oram ${ }^{1,5}$ (D)
}

Published online: 26 October 2021

(C) The Author(s) 2021

\section{Correction to: Diabetologia}

https://doi.org/10.1007/s00125-021-05513-4

Unfortunately, Kashyap Patel's name was spelt incorrectly. The original article has been corrected.

Publisher's note Springer Nature remains neutral with regard to jurisdictional claims in published maps and institutional affiliations.

The online version of the original article can be found at https://doi.org/ $10.1007 / \mathrm{s} 00125-021-05513-4$

Nicholas J. Thomas

n.thomas3@exeter.ac.uk

$\triangle$ Richard A. Oram

r.oram@exeter.ac.uk

1 Institute of Biomedical and Clinical Science, University of Exeter Medical School, Exeter, UK

2 Department of Diabetes and Endocrinology, Royal Devon and Exeter NHS Foundation Trust, Exeter, UK

3 Faculty of Medicine, Imperial College, London, UK

4 Pacific Northwest Research Institute, Seattle, WA, USA

5 Renal Department, Royal Devon and Exeter NHS Foundation Trust, Exeter, UK 